\title{
VAGOTOMY IN THE TREATMENT OF PEPTIC ULCERATION *
}

\author{
H. W. BuRge, M.B.E., F.R.C.S. \\ Honorary Surgeon, West London Hospital, W.6
}

The role of gastric hyperacidity in the etiology of certain forms of peptic ulceration is now firmly established. Any operation which claims to cure these ulcers must be shown markedly to reduce the gastric acid secretion, and to carry a low recurrence rate in a large series of cases in which none has been followed for less than five years, and preferably for not less than ten.

The operation of vagotomy can now fulfil these demands. It has won the race, leaving subtotal gastrectomy a poor second. It is interesting therefore to look back and to watch the race in retrospect.

\section{History}

In I88I Wolfler performed the first successful gastro-jejunostomy for duodenal ulceration. This operation became very popular, but by 1925 Berg and others had reported an anastomotic ulcer rate as high as 30 per cent. This figure, or an even higher one, is now regarded as true when gastrojejunostomy is performed for chronic duodenal ulceration.

Although the first successful gastrectomy was also performed in 1881 , this operation did not gain full favour until the bad results of gastro-jejunostomy were clearly known. In this field Austria and Germany were far ahead of all other countries. The Bilroth I gastrectomy was tried and discarded, and the Polya operation became the standard procedure throughout the world. England was slow to follow, and insisted; it would seem, in repeating all the mistakes of those early workers, determined to learn only by her own experience and not by that of others.

In Igro Pavlov published his famous experiments on sham feeding in dogs, and showed how much gastric acid secretion was dependent on intact vagus nerves. Exner was quick to recognize the value of this work, for only one year later he

*Based on a Hunterian lecture given to the Royal College of Surgeons on Thursday, November 5, 1959. The full text will appear in the Annals of the Royal College of Surgeons. considered, and in fact used, a vagotomy as a $\stackrel{\vec{\omega}}{\sigma}$ therapeutic measure in man. During the next $\vec{C}$ 20 years many reports were forthcoming on vagal 3 . nerve section in man, and the operation was used $\omega_{\infty}$ for all kinds of gastric disorders, both functional and organic.

The results seem never to have been clearly i established, but must have been disappointing, 음 for vagotomy was given up in every land. It was indeed fortunate for us all that after the First World War a young physiologist from North America was sent to Vienna to be trained as a surgeon. In Vienna Lester Dragstedt, from $\vec{P}$ Chicago, came to know the work of men who were making the history of gastric surgery. He was not then to know how permanently he wout write his own name beside theirs. In 1943 we find his paper reporting two cases of duodenal ulceration treated by transthoracic vagotomy. $\mathrm{He} \stackrel{0}{\circ}$ showed the high night secretion of acid in these $\varrho$ cases, and its reduction by vagal section (Drag- $\overrightarrow{0}$ stedt and Owens, 1943).

Here at last there seemed an operation for duodenal ulceration based on sound physiological principles and yet before many years passed the $\overline{0}$ operation virtually died out in every country. Vagal section, with the undrained stomach, gave $\frac{\sigma}{3}$ rise to profound and prolonged gastric stasis, and this in turn to eructation of foul wind and to응 diarrhoea. By the time it was known that some form of gastric drainage operation was imperative $\mathrm{O}$ after vagal section, a few reports of a disturbing $D$ recurrence rate appeared, and by $195^{\circ}$ in this country the operation was said to be ' in its coffin,' $\mathrm{N}$ and this was true also for every country in which it had been used. For my own part, I used it from I 947 to 1950 . I too learnt the unpleasant side- $\omega$ effects of vagal nerve division, and how to relieve them by gastro-jejunostomy, but like othere surgeons, gave up its use for fear of its failure to heal, and to keep healed, the ulceration.

\section{A Long-term Study}

It was already becoming clear at that time that 
complete division of the vagus nerve cured anastomotic ulceration after gastrectomy, no matter how large, or how chronic, the ulcers were. Indeed, large and chronic ulcers could be shown to heal within two weeks.

Although many surgeons in this country had a small series of cases, none was large enough for a satisfactory study. At the West London Hospital we resolved to establish a nation-wide series. Surgeons in many parts of England kindly allowed us to use their cases, and Mr. Alan Pollock laid down our series and published the results of his work (Pollock, 1952). During the next five years I used this operation only for cases of anastomotic ulceration after gastrectomy. In I956, Mr. John Lloyd Davies studied Pollock's series and reported the results at five years of two groups, one with gastro-jejunostomy and one with pyloroplasty (Lloyd Davies, 1956). His results are shown in Tables 1 and 2.

TABle I.-VAgotomy and Gastro-Enterostomy (Five years)

$\begin{array}{lcrrr}\text { Total number .. } & \ldots & \ldots & \ldots & 212 \\ \text { Lost to follow-up } & \ldots & \ldots & \ldots & 6(2.8 \%) \\ \text { Dead (other causes) } & \ldots & . & \ldots & 13(6.2 \%) \\ \text { Proved recurrence (anastomotic } & \text { ulcer) } & 7(3.5 \%) \\ \text { Gastric ulceration } & . & \ldots & \ldots & 2(1.2 \%) \\ \text { Stenosis requiring surgery } & \ldots & \ldots & 0(0.0 \%)\end{array}$

Table 2.-VAgotomy and Pyloroplasty (Five years)

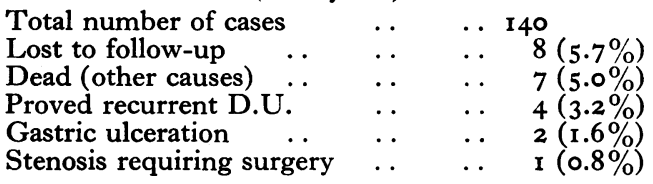

When these results became known I resolved to use vagotomy in all cases of chronic duodenal ulceration needing surgery, except when operation was undertaken as an emergency in massive haemorrhage, or when complicated by gastric ulceration or by perforation.

Two years later Dr. Ernest Pick and I studied again the series with gastro-enterostomy. We were able to include a group of cases in which consent to study was not given in the five-year review. It will be seen from Table 3 that no case was followed for less than seven years, and how very few remained untraced (Burge and Pick, I958).

\section{Table 3.-VAgotomy and Gastro-enterostomy FOR DUODENAL UlCER}

$\begin{array}{lllc}\text { Total number in series } & \ldots & \ldots & 301 \\ \text { Shortest follow-up } \quad \ldots & \ldots & \ldots & 7 \text { years } \\ \text { Lost to follow-up } \quad \ldots & \ldots & \ldots & 6 \\ \text { Died from other causes } & \ldots & \ldots & \text { r3 } \\ \text { Followed } 7 \text { to } 9 \text { years } . & \ldots & \ldots & 282 \\ \text { Proved. recurrence rate } & \ldots & \ldots & 4.5 \%\end{array}$

TABLE 4.-VAgotomy AND GASTRO-ENTEROSTOMY (Ten years)

$\begin{array}{lcccc}\text { Total number . } & \ldots & \ldots & \ldots & 301 \\ \text { Lost to follow-up } & \ldots & \ldots & \ldots & \text { I I } \\ \text { Dead (other causes) } & \ldots & \ldots & \ldots & 28 \\ \text { Number followed } & \ldots & \ldots & \ldots & 262 \\ \text { Recurrent ulcer (anastomotic) } & \ldots & \text { ro }(3.8 \%) \\ \text { Gastric ulcer } 0 & \ldots & \ldots & \ldots & 2(0.7 \%) \\ \text { Later operation for stenosis } & \ldots & \ldots & \text { I (0.3\%) }\end{array}$

Table 5.-Vagotomy and Pyloroplasty (Ten years)

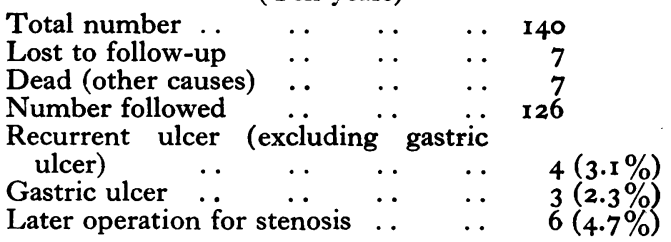

Dr. Peter Clark and I have recently studied again both series, and Tables 4 and 5 give the tenyear results.

The important finding in this long-term study is the low recurrence rate, comparing very favourably with subtotal gastrectomy. Even more important, however, is the very certain knowledge that probably 30 per cent. or more of cases had incomplete division of all vagal trunks. This important question of incomplete nerve section will be discussed later in this paper. If the recurrence rate is approximately 4 per cent., with an incomplete nerve section rate of 30 per cent., were not all, or almost all, recurrences due to retained intact vagus trunks?

\section{Vagotomy and Gastrectomy-A Comparison}

In both the five-year and the eight-year reviews, the results of vagotomy were compared with those of subtotal gastrectomy. I think this comparison is best given by quoting from the eight-year study.

\section{"Mortality}

The mortality of gastrectomy in expert hands is probably I to 2 per cent., but it seems that the overall mortality in this country is a good deal higher. The operation of vagotomy and gastroenterostomy exposes the patient to almost no risk either of mortality or of post-operative morbidity, for there is no inherent risk in the operation as there is in partial gastrectomy. We may regard the risk as that of gastrectomy less its inherent risks of stump leakage, haemorrhage, and loop obstruction.

\section{Recurrence Rate}

The proved recurrence rate of ulceration after partial gastrectomy probably varies from 2 to 6 per cent., depending upon the extent of gastric resection. The proved recurrence rate in our series of vagotomy and gastro-enterostomy is 
4.25 per cent. at eight years. Again we emphasize the high incidence of incomplete nerve section in this series.

\section{Nutritional State}

It is well known that after gastrectomy many patients cannot eat full meals, and, perhaps as a result of this, loss of weight is not uncommon. Ivy, Grossman and Bachrach (1950) found the post-operative weight steady or increased in 53 per cent. and decreased in 47 per cent. This is a very different figure from our findings after vagotomy and gastro-enterostomy, in which only ro per cent. showed weight loss.

\section{Post-operative Anaemia}

One of us (H.B.) has investigated anaemia after partial gastrectomy. The incidence of microcytic anaemia was shown to increase considerably with the passing years. A study of 300 male patients, 50 in each year group from one to six years after Polya gastrectomy, is shown in the following table.

Post-operative Incidence of Anaemia

\begin{tabular}{|c|c|c|c|c|c|c|}
\hline \multirow{2}{*}{ Haemoglobin } & \multicolumn{6}{|c|}{ Years after Gastrectomy } \\
\hline & $\mathbf{I}$ & 2 & 3 & 4. & 5 & 6 \\
\hline 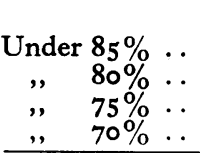 & $\begin{array}{r}\% \\
12 \\
6 \\
2 \\
0\end{array}$ & $\begin{array}{r}\% \\
12 \\
8 \\
6 \\
0\end{array}$ & $\begin{array}{r}\% \\
22 \\
10 \\
4 \\
0\end{array}$ & $\begin{array}{r}\% \\
32 \\
20 \\
14 \\
4\end{array}$ & $\begin{array}{r}\% \\
38 \\
26 \\
18 \\
6\end{array}$ & $\begin{array}{r}\% \\
58 \\
36 \\
24 \\
18\end{array}$ \\
\hline
\end{tabular}

It will be seen that post-operative anaemia after gastrectomy is a common condition. Often undiagnosed and untreated, it can result in considerable disability. As stated above, at eight years anaemia does not appear to be a complication of vago tomy and gastro-enterostomy.

\section{Physical State}

The physical fitness of patients after vagotomy and gastro-enterostomy is very much better than after gastrectomy. Not many patients return to heavy manual work after gastrectomy.

\section{Change of Bowel Habit}

We have written already at some length about this symptom after vagotomy and short circuit. The same symptom occurs after gastrectomy and, as with vagotomy and short circuit, it has been brought to light only by direct questioning. In a series of 200 post-gastrectomy patients, in reply to the direct question, 'Do you have diarrhoea or loose motions ?', 20 per cent. replied in the affirmative... This compares with 30 per cent. after vagotomy and short circuit. Exactly the same pattern exists in both operations, but the attacks occur somewhat less often after gastrectomy.

\section{Post-cibal Symptoms}

There is no need to state here the incidence and $C$. severity of post-cibal symptoms after gastrectomy. $\overrightarrow{\vec{F}}$ These are only too well known. It is generally? agreed that the incidence and severity of these symptoms after gastrectomy are related to the $\frac{\bar{c}}{\bar{c}}$ extent of gastric resection. The operation of $\frac{\vec{\sigma}}{\vec{\alpha}}$ vagotomy and short circuit carries with it a much $\cong$ lower incidence and less disability.

\section{Bilious Regurgitation}

As with the post-cibal ' dumping' symptoms, so $\vec{\omega}$ with bilious regurgitation, the incidence and severity are much less after vagotomy and gastroenterostomy than after gastrectomy."

The only disturbing feature of vagotomy when compared with gastrectomy was the incidence of $\vec{i}$ permanent and troublesome diarrhoea. It seemed 0 to us at this stage in our work that if incomplete vagal nerve section could be guaranteed at opera- $\vec{c}$ tion, and if the cause of post-vagotomy diarrhoea could be found and the symptom prevented, then gastrectomy would, except in a few instances, have $₹$ no place in the treatment of duodenal ulceratio $\vec{\theta}$

Two problems then seemed clearly before uS and we set out to investigate each in turn.

\section{The Problem of Incomplete Nerve Section}

As early as 1925 it was known that a large inection of insulin in animals caused a gastric acid response, and that this response was dependent on intact vagus nerves. From this knowledge developed the Hollander Insulin Test Meal. It seems that this test is not always reliable, especially when the stomach is drained by gastro-jejunostomy. What is more important however, is that it can only be used when the patient is well after operation. Only then can it be shown that the operation was not properly performed.

Dragstedt has always firmly held the view that recurrent ulceration was invariably, or almost 0 invariably, due to incomplete nerve section. Using the insulin test meal in cases of vagotomy and pyloroplasty, Stempien, Dagradi and Seifer (1959) found an incomplete nerve section rate of or 38 per cent. In the early years of vagotomy this $N$ was probably a common incomplete section rate. N

\section{The Electrical Stimulation Test}

Dr. John Vane and I (Burge and Vane, 1958), because of this problem of incomplete section, $\stackrel{\oplus}{+}$ developed and described a test which can be used $T$ to demonstrate complete section at operation in man. Not only will the test detect any nerve 


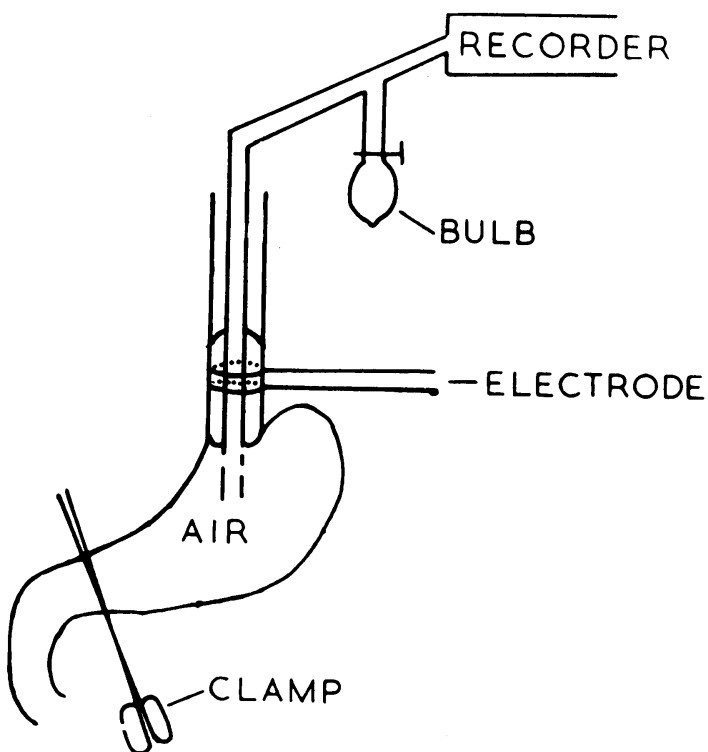

FIG. I.

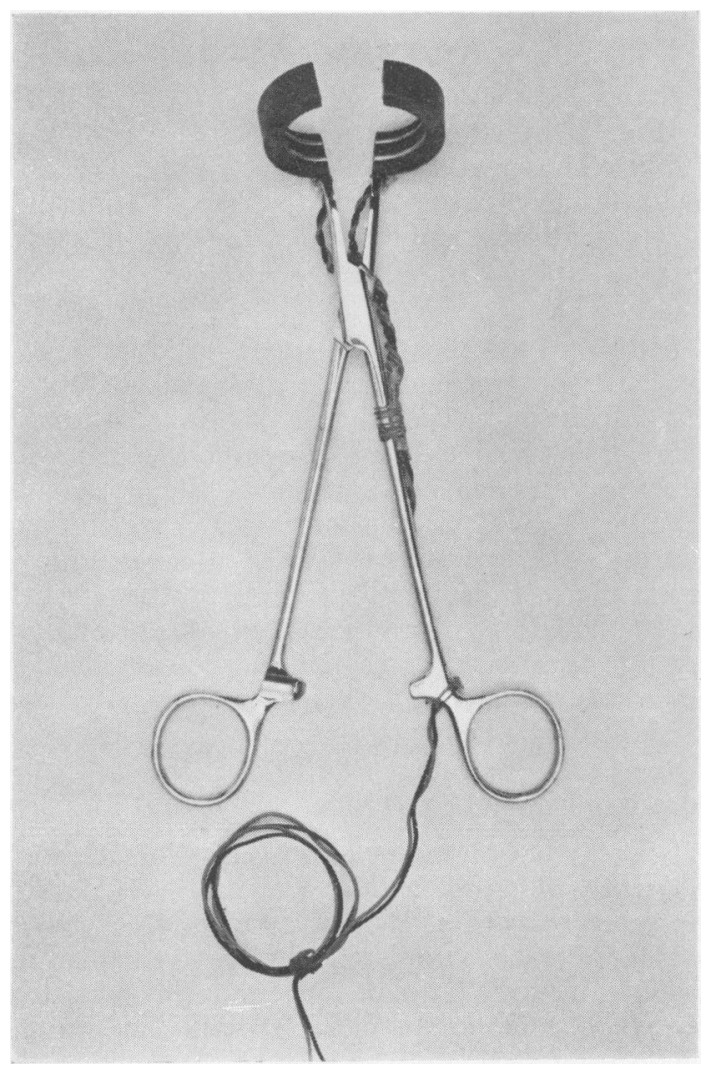

FIG. 2.

trunks left undivided, but will localize these to a quadrant and so allow the surgeon to look again at

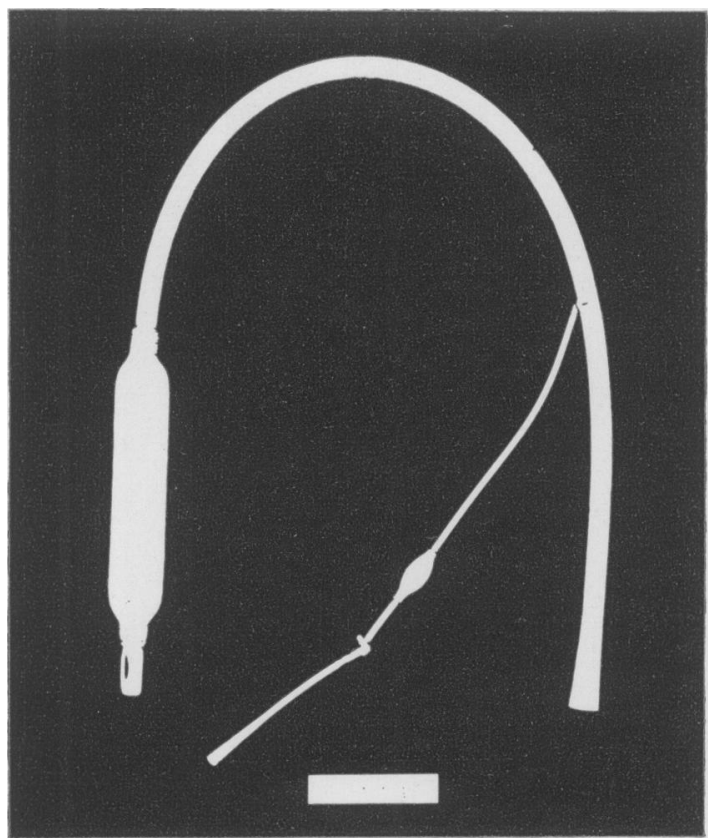

FIG. 3 .

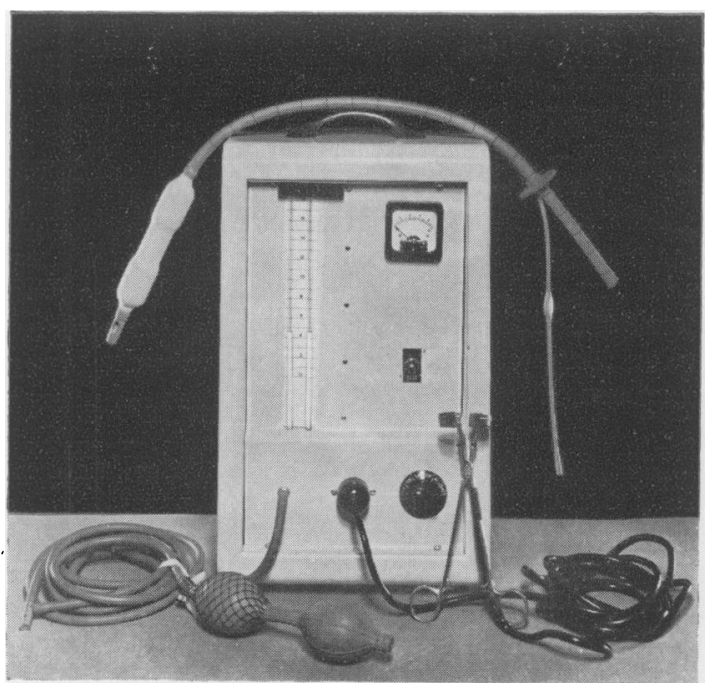

Fig. 4 .

that quadrant for small nerve trunks.

Chamberlin and Winship (1947), Dragstedt et al. (1947) and Jackson (1949), were all led to study the anatomy of the vagus nerves following Dragstedt's important early work. All these workers showed that both the anterior and the posterior nerve trunks, both above and below the diaphragm, may exist as more than one trunk. Indeed, Jackson showed that in 28 per cent. of 50 

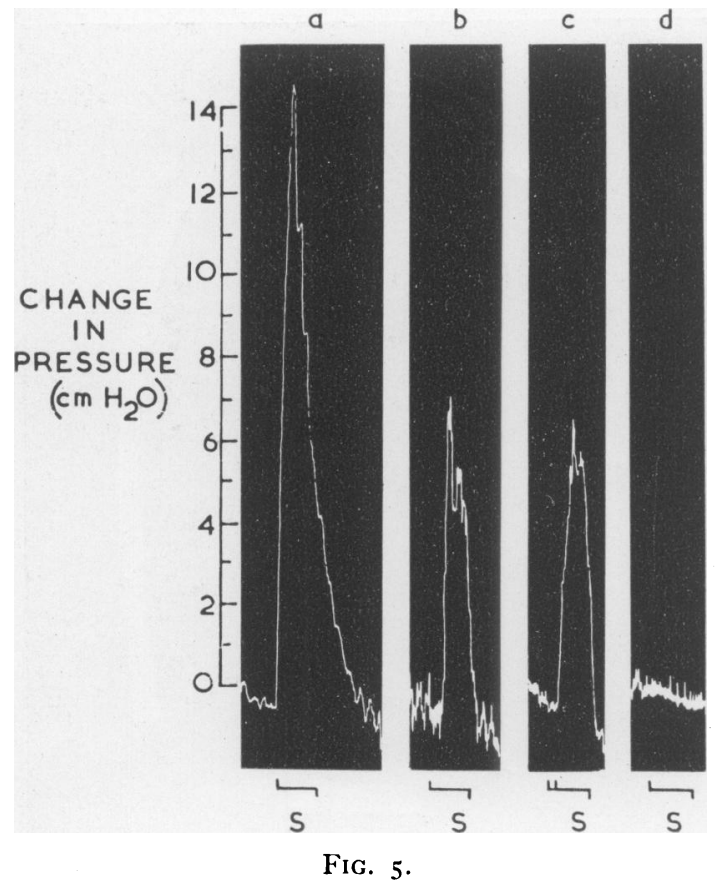

Fig. 5.

cases, the anterior nerve entered the abdomen as two trunks.

The principle of the test is shown in Fig. I. An electrode, Fig. 2, divided into four quadrants, is placed around the lower oesophagus. This is best done after the anterior vagus has been divided, for then the intra-abdominal oesophagus is longer and the instrument is more easily applied. A cuffed gastric tube (Fig. 3 ) is passed into the stomach and the cuff inflated with air. In this way the lower oesophagus is sealed and the vagus nerves brought into contact with the electrode. A clamp is placed across the gastric antrum and the stomach inflated with air to a pressure of approximately $20 \mathrm{~cm}$. of water. The gastric pressure is recorded on a simple water manometer. Fig. 4 shows the apparatus in its present form. The stimulator producing the current is transistorized and batteryoperated. It is built in the same case as the manometer. Two water manometers are used, one of which responds to respiratory phase and the other has respiratory effect damped out. Fig. 5 shows a recording in man taken from a water manometer writing on a smoked drum. After the main anterior and posterior nerves were divided a considerable increase of pressure was recorded, until the third trunk was found and divided. It has long been known that a small nerve trunk will give rise to considerable motor response, and probably too, to considerable secretory function. The stimulation test has proved extremely sensitive.

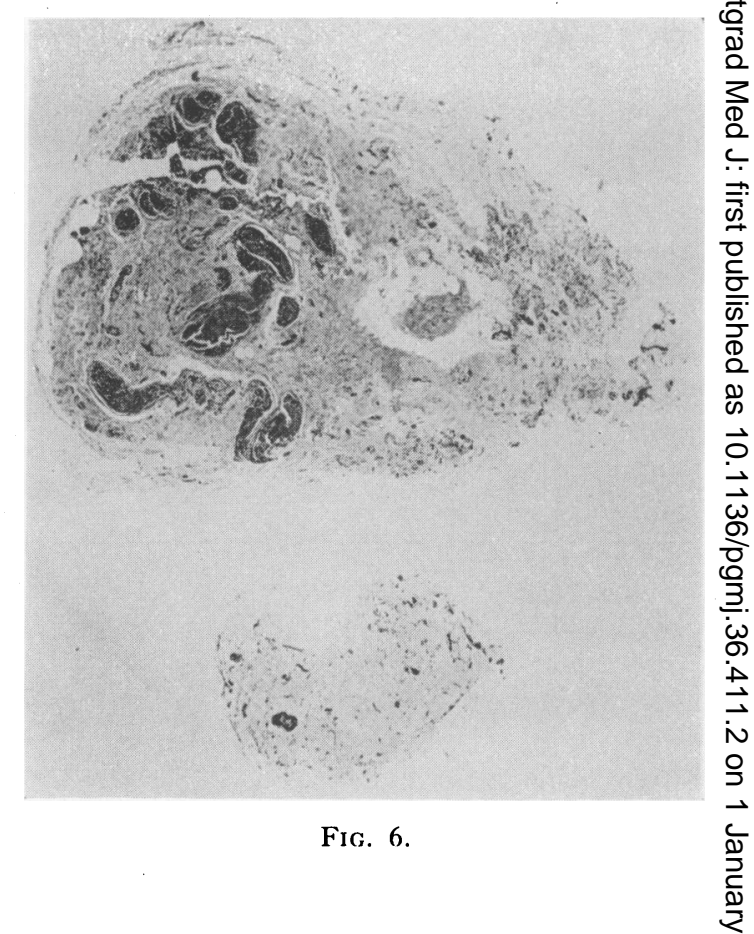

In Fig. 6 the larger nerve is the main posterigr $\overrightarrow{0}$ trunk. The smaller one, consisting only of two small bundles, was not found at operation untilat had been demonstrated and localized by the tes? It gave rise to an increase of $I \mathrm{~cm}$. of water pressure.

Although surgeons very experienced in vago- $\frac{\emptyset}{\not}$ tomy may do excellent work without such a test as $\stackrel{\varrho}{\Rightarrow}$ this, which can be used during operation, it would $\overrightarrow{\overrightarrow{0}}$ seem only sensible to use a method which will allow of complete nerve section. Stempien and Weinberg (1953) described I I cases in which they had operated for recurrent ulcer after vagotomy. $\frac{3}{3}$ In six the main right vagus was found intact and in one the left. In two cases adhesions prevented 3 . a search for intact nerves, and in one case a smallio nerve was found. In the remaining case no nerve trunk could be demonstrated.

\section{Post-Vagotomy Diarrhoea}

In each of our long-term studies we investigated the change of bowel habit after vagotomy. During or the years 1947-1950, although we were conscious 0 of some diarrhoea while the patients remained in $N$ hospital, we were quite unaware that this persisted permanently in some cases. As with the 'dump-co ing' after gastrectomy, so with this symptom, the patient may suffer in silence at home with the? surgeon quite content that the condition does not $\frac{T}{0}$ exist. When we compared the incidence and $\stackrel{\vec{D}}{\vec{D}}$

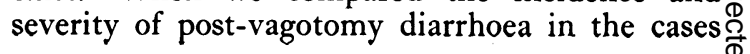




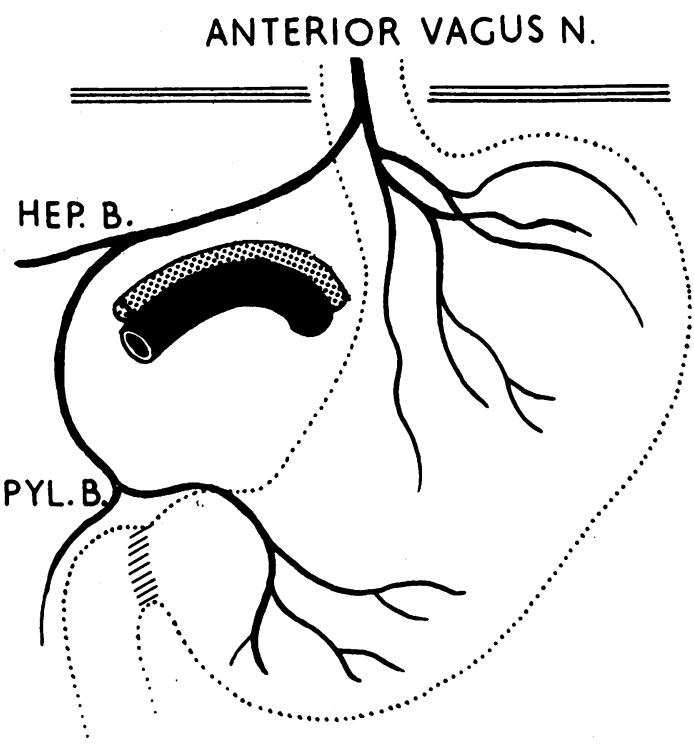

Fis: 7 .

from each city, we found almost exactly the same picture. Both at five years and at ten, some 30 per cent. stated that they had some diarrhoea or loose motions. Many were pleased that the preoperative constipation was cured. However, many had what seemed to be troublesome symptoms. The most common picture took the form of attacks occurring every few weeks and lasting from one to three days, with three to four loose or liquid motions daily, with urgency. Sometimes there was an early morning diarrhoea with urgency which was troublesome for patients about to leave home for work. Several workers have written on this subject. Ruffin and Smith (1946) reported the symptom in 40 per cent. of cases, and Smith et al. (1947) in 50 per cent. Collins et al. (1948) reported 36 per cent. These figures all agree very closely with our own. Severe diarrhoea fortunately is rare and occurs in not more than 2 to 3 per cent.

A very marked change in colour of the stools was recorded in our cases in a very high percentage. The stools were pale and bulky, suggesting pancreatic deficiency. A satisfactory explanation of this colour change has not been given. Sometimes gastric stasis is put forward as the cause of the diarrhoea, but barium meal studies fail to support this theory. Intestinal infection secondary to a low gastric acidity has never been supported by isolation of causal organisms. Clearly the cause of the pale loose motions is not known.

The character of the stools led us to study the vagal innervation of the pancreas, and the anatomy of the abdominal vagus nerves. Several excellent papers have been written on the subject,

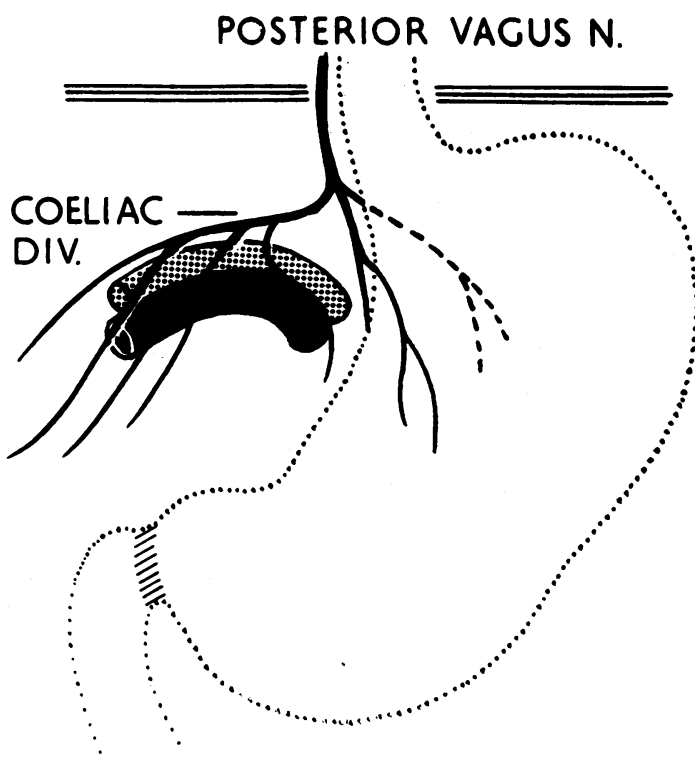

Fig. 8 .

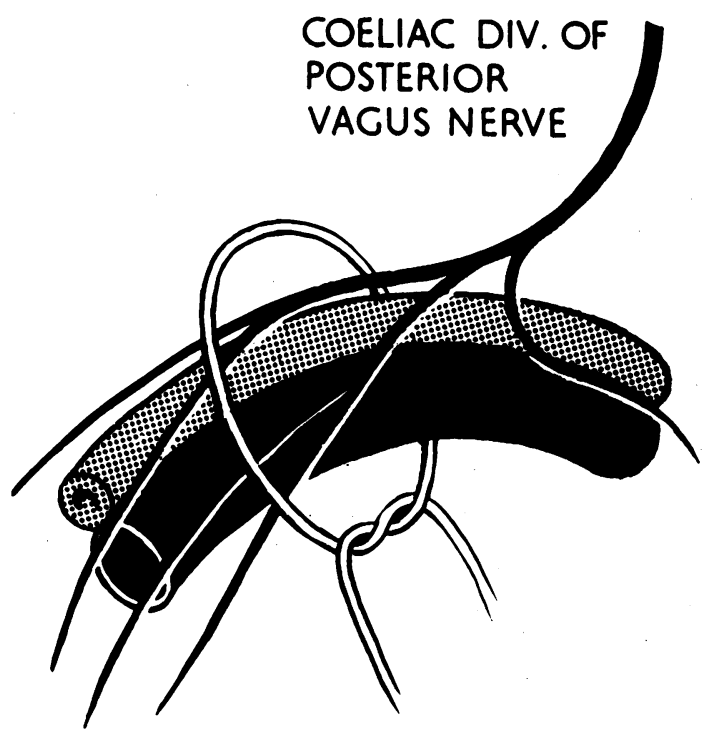

FIG. 9.

in particular Jackson's paper of 1948 . The main features of the anatomy of the anterior nerve are shown in Fig. 7. It gives off a hepatic branch which runs to the portal fissure in company with a branch of the ascending branch of the left gastric artery. This hepatic branch gives a pyloric branch which supplies the pylorus and sends gastric branches in the small omentum. Fig. 8 shows the posterior nerve with its large coeliac division, which passes to the coeliac plexus. It is interesting to note that when the left gastric artery is tied during gastrectomy on the posterior 


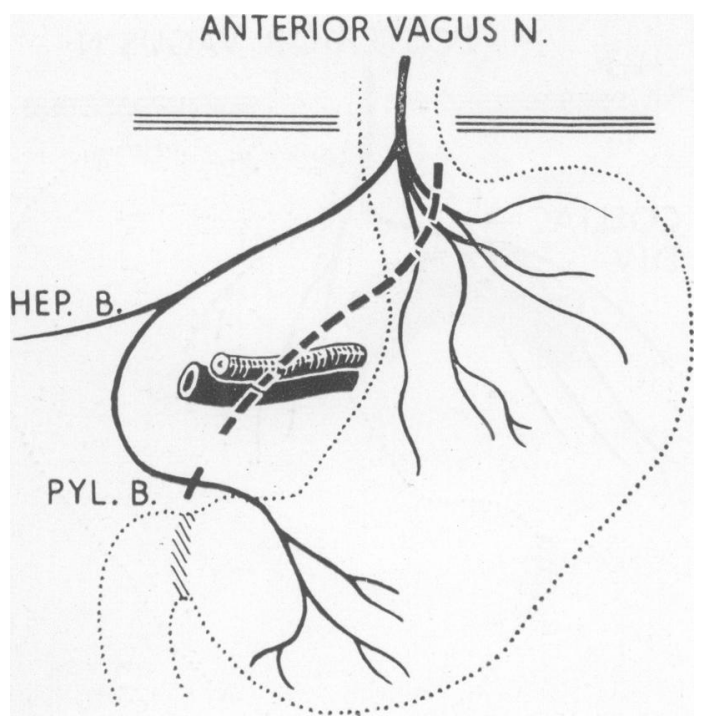

Fíg. 10.

abdominal wall, the ligature includes this coeliac division (Fig. 9). Perhaps it is fortunate that most surgeons today, in performing gastrectomy, ligate the left gastric artery on the lesser curve and not at its origin.

Considerable experimental work in animals has been done on the effect of vagal nerve section on pancreatic and on hepatic function, and such work has suggested that the vagus plays no important role in the working of these organs. However, we determined to preserve the coeliac division of the posterior nerve while dividing all other branches, in an attempt to prevent postoperative diarrhoea. After we had done this we found that Franksson (1948) and Jackson (1948) had considered preserving the vagal innervation of other organs while dividing all gastric branches. Both these workers performed selective vagotomy, preserving the coeliac division of the posterior nerve and the hepatic division of the anterior nerve, but neither, it seems, applied this specifically to the prevention of post-operative diarrhoea. When vagotomy died, soon after this, their work seems to have been forgotten, for the most enthusiastic supporters of vagotomy have not since advocated a selective operation.

We can now record a small series of cases with complete division of the anterior nerve and presirvation of the coeliac division of the posterior, and another small series in which the hepatic division of the anterior is also retained. When this has been done the pyloric branch of the hepatic branch has also been preserved, and the ascending gastric branches dealt with, by division of the small omentum down to muscle just to the left of the pylorus. Figs. Io and I I indicate the site of

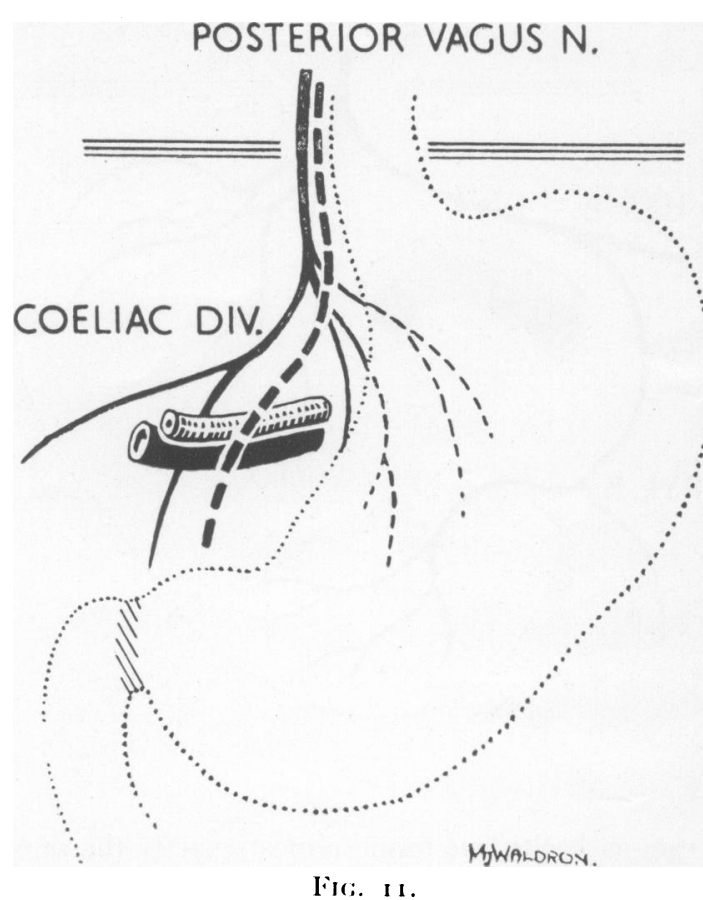

IFIG. II.

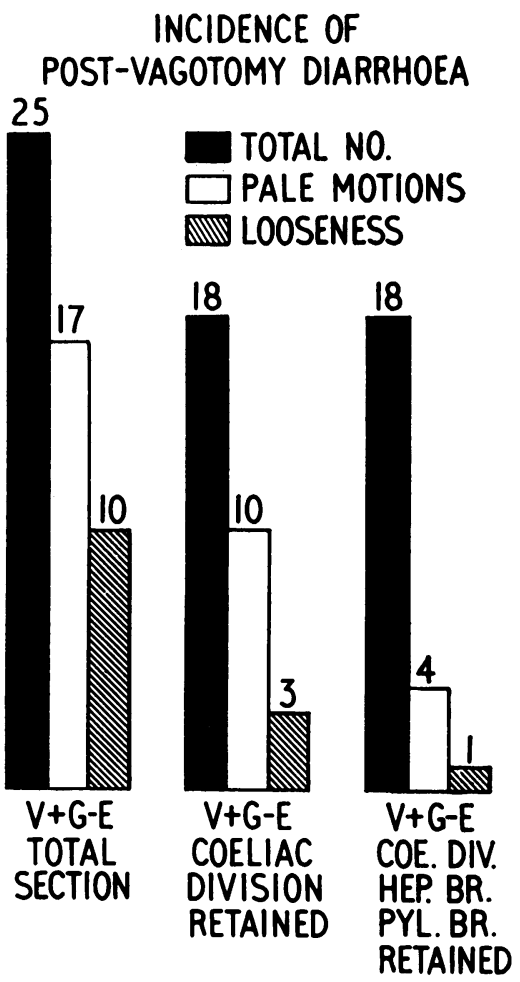

Fig. 12. 


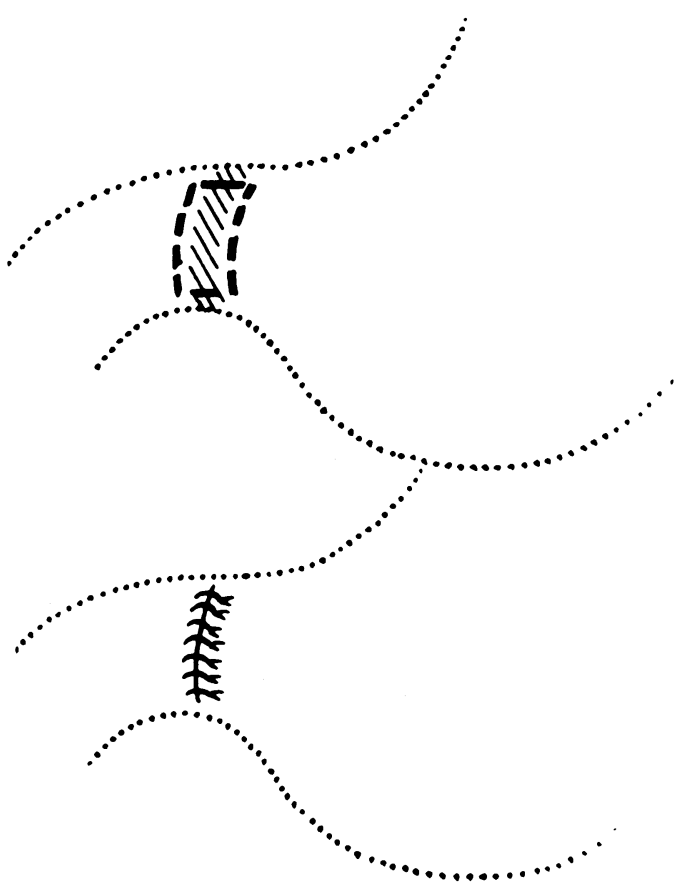

Fic: 13 .

division of the branches in this bilateral selective vagotomy. Fig. 12 compares the incidence of pale motions and of diarrhoea in these two series with another in which complete division of all nerves was done. From these findings, and from the observations of our ward sisters and ourselves while the patients are in hospital, we believe that there is very strong evidence that the preservation of these branches is important in maintaining the normal colour of the motion and its consistency. We are at present working closely with colleagues in Glasgow, and hope before very long to publish a careful study of a large series which will prove, or disprove, the already strong evidence we have. Perhaps the most remarkable thing seems to be, that preservation of the hepatic branch of the anterior nerve is the important factor in retaining the faecal colour. Perhaps this nerve controls in some way the mechanism of biliary secretion into the gut.

The work of Jackson on the anatomy of these nerves has made it quite clear that when performing selective vagotomy on the posterior nerve, the left gastric artery and vein must be divided, for the coeliac division itself supplies gastric branches running along this vessel.

\section{Gastric Drainage Operations}

Our long-term studies have shown that pyloroplasty is as good an operation as gastro-jejunostomy

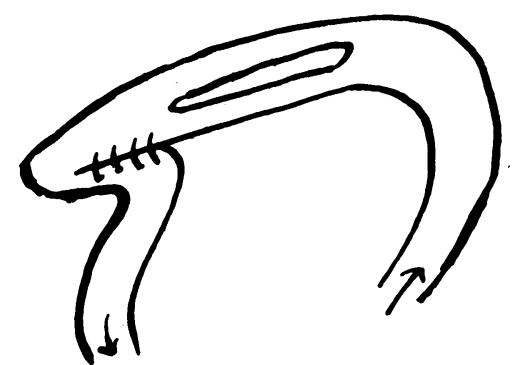

Fig. If-Ant. oblique G-E efferent limb adhesion.

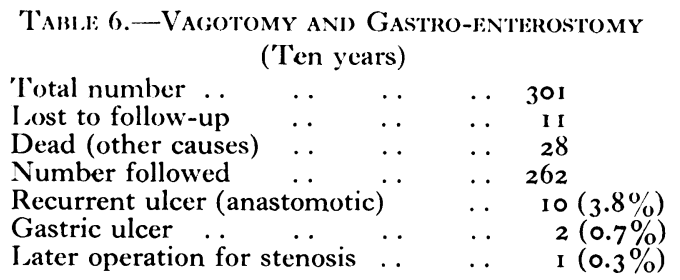

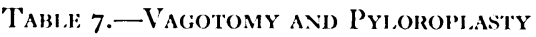
('Ten years)

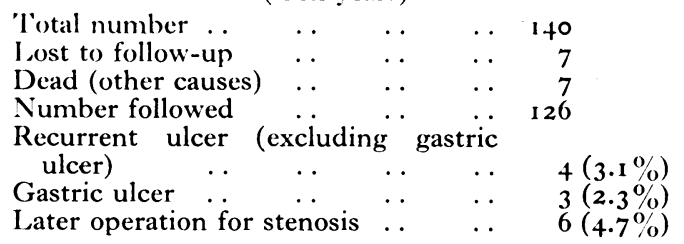

from the point of view of cure of ulceration. Tables 6 and 7 again show the ten-year results, and from these it will be seen that the incidence of gastric ulceration was higher when pyloroplasty was used. When this complication occurred there was pyloro-duodenal stenosis. Such stenosis is brought about either by performing pyloroplasty in the presence of unnoticed duodenal narrowing, or by too much infolding of the duodenal wall. For this reason more cases of pyloroplasty came to later gastrectomy than cases with gastrojejunostomy, for stenosis after this latter operation has only arisen when a very small stoma has been made in the presence of severe duodenal block. In the pyloroplasty series there was a small incidence of death from leakage, a complication quite absent in the gastro-jejunostomy group. Pyloroplasty should therefore be used only when there is no duodenal narrowing, and when the surgeon feels that he can perform it with safety yet leaving a good wide stoma. Although anterior pylorectomy has not been reviewed in this investigation, it is probably a better operation than pyloroplasty and we perform it by excising no more than the anterior pyloric muscle ring (Fig. 13).

Gastro-jejunostomy itself carries many problems, and these were all recorded during its 


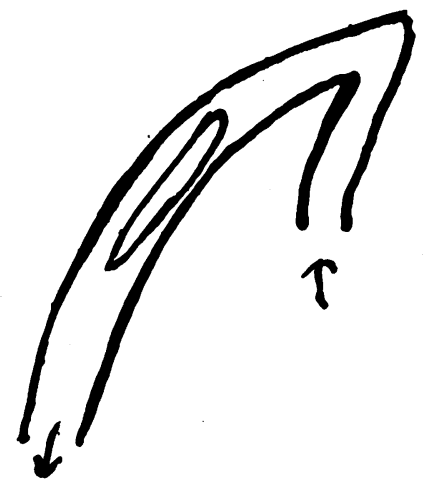

Fig. 15.-Post G-E afferent loop too tight.

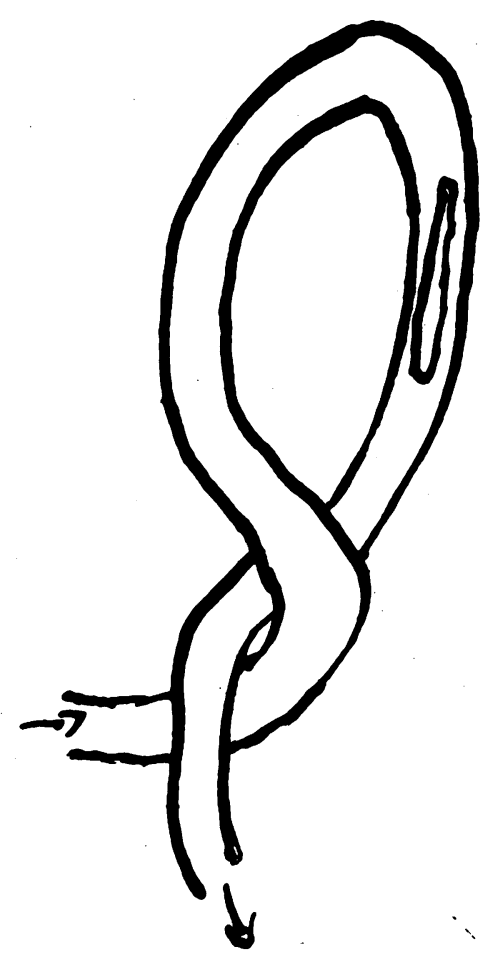

Fig. 16.-The twisted loop.

early days. In our own early work, from 1947 to $195^{\circ}$, we used the standard posterior vertical stoma of adequate size, and seemed to have little trouble. When later we returned to vagotomy, we used an oblique anterior anastomosis, on the grounds that if recurrent ulceration occurred, gastrectomy would be more easily done. During this time we met with a number of complications, all of which have been described in the past. We saw the efferent loop adhesive block, as shown in Fig. 14. This would not have happened with a vertical stoma. We saw the afferent loop block from too tight a loop (Fig. I5), and trouble

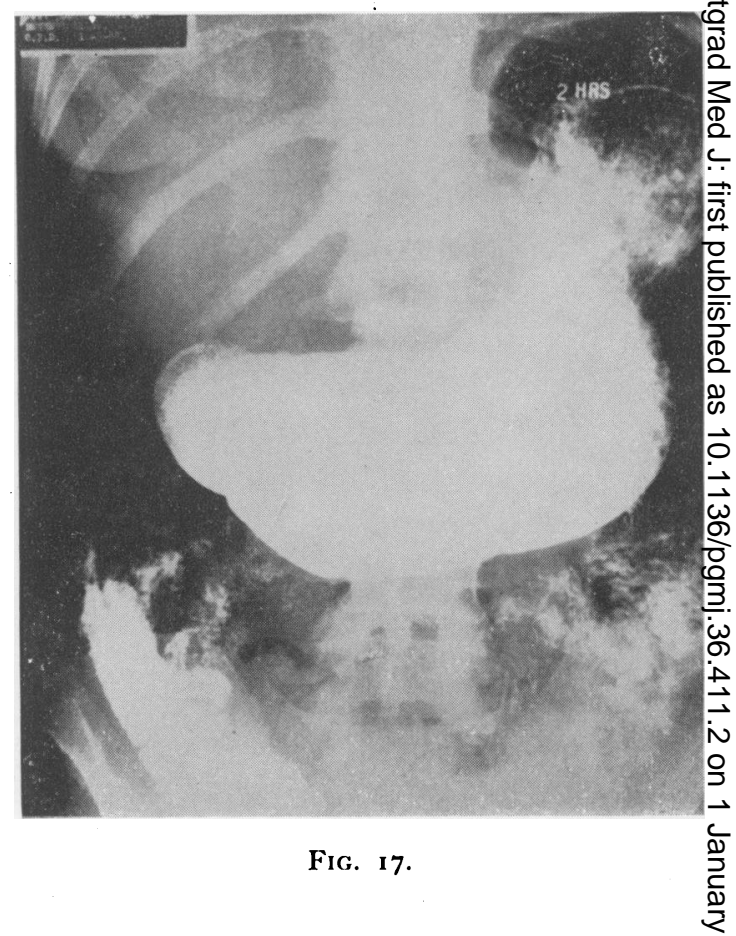

from the small bowel loop twisted inadvertendy $\overrightarrow{0}$ during operation (Fig. I6). The so-called viciows circle vomiting of days gone by appears to be die to an efferent or afferent limb block, and enormove quantities of bile-stained gastric contents are aspirated. Since we returned to the posterion vertical stoma of good size, we have been freed from trouble. The afferent limb should be loose and the vertical efferent limb seems free fromp kinking, and it was not without reason that Moynihan laid down his principle. There seems no reason for making the posterior stoma very close to the pylorus. Indeed, if this is done is may be made too small and lead to gross gastric: delay if duodenal stenosis exists. An X-ray o $\mathrm{B}$. one patient in which this happened is shown irg Fig. 17. At subsequent gastrectomy a very smalB stoma was found and severe duodenal stenosis.

\section{Post-operative Care}

After operation we have used gastric suction by Ryles tube, with immediate fluids by mouth, and have taken up the tube when the gastric balance्s has been strongly positive. Usually this occurso 36 hours after operation. Rectal salines have beep given, although it is possible to nurse these patients without giving fluids by any but the ora廆 route. To use a gastrostomy of any kind in the post-operative management seems unnecessary and unsound.

My comments so far have been concerned witl 
chronic duodenal ulceration. Vagotomy, however, has its use in other conditions.

\section{Vagotomy in Perforated Duodenal Ulcer}

For many years immediate subtotal gastrectomy has been used in the treatment of perforated duodenal ulcer when the case is early and already has a long history of much trouble. We have been tempted to perform vagal nerve section, with its test for completeness, with suture of the perforation, and posterior gastro-jejunostomy, in such cases. It would seem that the only possible disadvantage of this method might be the risk of sepsis in the extra-peritoneal tissues exposed during operation. We have not yet had experience of this, and we feel that the operation may be preferable to gastrectomy for this condition.

\section{Vagotomy in Anastomotic Ulceration}

During the early years when the late results of vagotomy were unknown, it was already apparent that vagal nerve section would cure anastomotic ulceration after gastrectomy, either of the Polya or the Bilroth I type. Healing of large and chronic ulcers would take place within 14 days of operation, and long-term studies have confirmed the permanence of cure. There seems to be no need in these cases to excise a chronic ulcer, and even when the gastric remnant seems to be too big, there is probably no need to perform a higher gastrectomy. Perhaps the only exception to this cure by vagotomy is when anastomotic ulceration is caused by tumours, as in the Zollinger-Ellison syndrome. There is little doubt that the Bancroft technique of dealing with a difficult duodenal stump during gastrectomy, does carry with it an increased risk of anastomotic ulceration, for complete mucosal ablation is seldom achieved, and a very small gastric mucosal remnant seems to be able to produce anastomotic ulceration. Vagotomy, in these cases, heals the anastomotic ulcer, and if the Bancroft operation is used to avoid leakage in a difficult stump, probably vagotomy should be performed at the same time.

\section{Vagotomy in Simple Peptic Oesophageal Stricture}

Severe, simple, oesophageal stricture from peptic oesophagitis and ulcer, is not uncommon, and is most frequently seen in frail, elderly women. Medical treatment appears quite unsatisfactory, and abdomino-thoracic total gastrectomy, with excision of the stricture, and oesophago-jejunal anastomosis, is a severe operation in such cases. Not only must it carry a considerable mortality and immediate morbidity, but it must carry also all the late complications of total gastrectomy and complete vagotomy. Sub-total gastrectomy with- out interference with the stricture, has for some time been used in this condition with gratifying results. One patient with a severe stricture and oesophageal dilatation, we treated by a very high gastrectomy with splenectomy, and have watched the progress of the stricture for six years. The result is excellent, and is due presumably to excision of the gastric acid-forming area and a change in the character of the refluxing fluid, now a mixture of gastric and jejunal juices.

It would appear, therefore, reasonable to aim at the same result by vagotomy and gastro-jeunostomy, for many of these patients have associated duodenal ulceration and probably a high nocturnal acid secretion. Mr. A. M. B. Tompkin and I have recently used this method in a patient who, for a long time, had been unable to eat solid food, and who had a fairly tight stricture of the oesophagus. Duodenal scarring was found at operation. Selective vagotomy and posterior gastrojejunostomy was performed. The result has been quite remarkable on clinical and radiological evidence. These cases of stricture are due to oedema and spasm, and to associated fibrosis. When the active disease is cured, the oedema and spasm rapidly disappear, and even what would seem to be the residual fibrosis, opens up with the passing years.

\section{Vagotomy in Hiatus Hernia with Oesophagitis}

When hiatus hernia is associated with oesophagitis, but without stricture, it is desirable to repair the hernia and make an effort to control reflux. Encouraged by the results of our experience of vagotomy and gastro-jejunostomy in simple peptic oesophageal stricture, Mr. Tompkin and $I$ have used the operation in a case of hiatus hernia with severe oesophagitis. The barium meal of this patient showed only early oesophageal spasm associated with a large sliding hernia. The oesophagoscope passed easily into the hernia, but the oesophagus showed gross haemorrhagic oesophagitis, and the patient needed blood transfusion to restore her haemoglobin. Bilateral selective vagotomy was performed, with gastro-jejunostomy and abdominal repair of the hernia. This patient now is entirely free from symptoms of reflux on lying down at night, and the dysphagia which troubled her before operation is cured.

It may well be that vagotomy and gastrojejunostomy, with repair of the hiatus hernia by the abdominal route, should be carried out in these cases before the pathology is too advanced.

\section{Vagotomy in Hiatus Hernia without Oesophagitis}

Operation not infrequently becomes necessary 
in hiatus hernia without oesophagitis, from symptoms of reflux or of obstruction. 'The results of repair of these herniae have not been very satisfactory, and surgeons have debated the best method of approach and the best technique. At the West London Hospital we have studied the results of abdominal and thoracic repair, and we were forced to conclude that the operation was more successfully undertaken through the chest. However, we noticed that during the operation of vagotomy, after division of the vagus nerves, the abdominal oesophagus became very long when untethered by the vagus strings. It was clear, on a little thought, that the gastric cardia could be easily sutured to the diaphragm to the left of the hiatus, after division of the nerves. Indeed, it seems probable that the abdominal repair of a hernia after vagal nerve division might prove the most successful of all methods. As too, a number of these cases have duodenal ulcers and acid reflux, it might well be that they would benefit from the decreased acidity and gastric drainage. Mr. A. M. B. Tompkin and I have therefore used the method in uncomplicated hiatus hernia, when surgery was indicated. Later, perhaps, we shall be able to report the results of a series of cases in which this has been done.

\section{Conclusion}

From our studies over a i2-year period we have drawn the following conclusions:

(I) That complete vagal nerve section is the treatment of choice in chronic duodenal ulceration, except when surgical treatment is undertaken for massive haemorrhage or when duodenal ulceration is accompanied by gastric ulcer.

(2) That the high incidence of incomplete nerve section in the past makes it desirable that a test for completeness should be used during operation.

(3) That in comparing vagotomy and gastrectomy, post-operative diarrhoea is the only symptom which weighs against vagotomy.

(4) That there is strong evidence that preservation of the hepatic branch of the anterior nerve and the coeliac division of the posterior nerve are important in the prevention of post-vagotomy diarrhoea.

(5) That given complete nerve section there is no need to perform low gastrectomy or antrectomy. A well-performed drainage operation in the form of either gastro-jejunostomy, pyloroplasty, or pylorectomy, is all that is required.

(6) That vagotomy with gastro-enterostomy and suture of the perforation may prove the operation of choice when indications are present to add at curative procedure at the time of operation for perforation.

(7) When vagotomy is performed for anasto- $\stackrel{\unrhd}{\varrho}$ motic ulceration after gastrectomy, there is no $c$ need to excise the ulcer no matter how large or $\overrightarrow{\mathrm{s}}$ how chronic the ulcer may be. Probably, too, $\rightarrow$ there is no need to perform further gastrectomy, even if the previous gastric excision seems to be $\overline{\bar{m}}$ inadequate.

(8) That vagotomy and short-circuit is probably $\frac{\Omega}{\Omega}$ the operation of choice in simple peptic oesopha- कs geal stricture.

(9) That the repair of hiatus hernia, with oesophagitis, should be combined with selective $\bar{\sigma}$ vagotomy and gastro-enterostomy.

(I0) That division of the vagus nerves, by increasing the length of the intra-abdominal oesophagus, allows of a repair probably better than can be obtained by either the thoracic or $\vec{A}$ abdominal route, when the vagus nerves are $\vec{i}$ intact. That vagotomy with gastro-enterostomy, 을 or a pyloric operation, should be combined with ${ }_{-}$ abdominal repair.

We seldom now hear the opponents of vagotomy criticize the operation on the grounds of recurrence. Indeed, given complete nerve section, $\vec{\bullet}$ we may perhaps criticize sub-total gastrectomy ㅇํㅇ these grounds. Both operations carry some inct dence of diarrhoea as a complication. If the selective operation can prevent post-vagotomy diarrhoea, and we think it can, then no case can be made out for excising any part of the stomach $\frac{\mathbb{}}{\mathbb{Q}}$ for chronic duodenal ulceration.

\section{REFERENCES}

BURGE, H., and PICK, E. J. (1958), Brit. med. F., i, 61 3 .

BURGE, H., and VANE, J. R. (1958), Ibid., i, 6r 5.

CHAMBERLIN, J. A., and WINSHIP, T. (1947), Surgery, 22, I COLLINS, E. N., CRILE, G., and DAVIS, J. B. (1948), Gastroenterology, 2, 453.

DAVIES, J. A. L. (1956), Brit. med. f., ii, 1086.

DRAGSTEDT, L. R., FOURNIER, H. J., WOODWARD, E. R, TOVEE, E. B., and HARPER, P. V. (1947), Surg. Gynec. Obstet., 85, $46 \mathrm{r}$.

DRAGSTEDT, L. R., and OWENS, F. M. (1943), Proc. Soc. exp. Biol. Med., 53, 152.

FRANKSSON, C. (1948), Act. chir. scand., 96, 409.

IVY, A. C., GROSSMAN, N. I., and BACHRACH, W. H. (I950), 'Peptic Ulcer'. London: J. and A. Churchill.

JACKSON, R. G. (1948), Arch. Surg., 57, 333.

JACKSON, R. G. (1949), Anat. Rec., I03, I.

POLLOCK, A. V. (1952), Lancet, ii, 795.

RUFFIN, J. M., and SMITH, R. C. (1946), Amer. Practit., r, I $18 . \mathrm{N}$ SMITH, R. C., RUFFIN, J. M., and BAYLIN, G. J. (r947), N

STEMPIEN, S. J., DAGRADI, A. E., and SEIFER, H. W. $\omega$ (1959), 'World Congress of Gastroenterology', vol. 2, p. 1026. Baltimore: Williams and Wilkins Co.

STEMPIEN, S. J., and WEINBERG, J. A. (r953), Ұ.A.M.A., I52, 1593 . 